\title{
ATIVIDADE MICROBIANA DO SOLO E PRODUTIVIDADE DO MILHO EM FUNÇÃO DA APLICAÇÃO ANTECIPADA DE NITROGÊNIO E ADENSAMENTO DE PALHA $\left({ }^{1}\right)$
}

\author{
WALDO ALEJANDRO RUBÉN LARA CABEZAS ( $\left.{ }^{2}\right)$
}

\begin{abstract}
RESUMO
As restrições climáticas na Região Noroeste paulista, aliadas à baixa altitude, são fatores limitantes para a cultura de milho. Os aumentos da atual produtividade são dependentes principalmente do manejo, devendo ser aprimorada a adubação nitrogenada. Portanto, foi desenvolvido um experimento no Pólo Regional Noroeste Paulista, município de Votuporanga (SP), em Argissolo de textura arenosa $\left(100 \mathrm{~g} \mathrm{~kg}^{-1}\right.$ de argila), objetivando-se avaliar a produtividade de grãos e a atividade respiratória da biomassa microbiana, quando efetuada a cobertura nitrogenada de forma antecipada à semeadura e de forma tradicional, em duas condições de adensamento de palha $\left(5.120 \mathrm{~kg} \mathrm{ha}^{-1}\right.$ e $\left.3.648 \mathrm{~kg} \mathrm{ha}^{-1}\right)$. Utilizou-se o delineamento de blocos casualizados, em esquema de faixas, para as épocas de adubação em cobertura e a adensamento de palha. Na cobertura nitrogenada foi utilizado sulfato de amônio, parcelado em duas vezes, em doses de 70 e $40 \mathrm{~kg} \mathrm{ha}^{-1}$ de N, aplicado em faixa superficial, na entrelinha. As épocas de aplicação foram: a) 59 e 45 dias antes da semeadura de milho, b) 21 e seis dias antes da semeadura e c) em cobertura tradicional, 22 e 46 dias após a semeadura, nos estágios respectivos V5 e V8, em triplicata, nas duas condições de adensamento de palha. Conforme os resultados, houve efeito positivo na atividade respiratória em função do umedecimento do solo, com aumento da evolução de $\mathrm{C}-\mathrm{CO}_{2}$ após as precipitações pluviais registradas nas três épocas de aplicação de $\mathrm{N}$ em cobertura. Não houve efeito significativo na atividade respiratória após a aplicação de $\mathrm{N}$ nas três épocas e, tampouco, devido ao adensamento de cobertura morta. A média de produtividade em sistema adensado, independentemente da época, foi de $5.762 \mathrm{~kg} \mathrm{ha}^{-1}$ de grãos e no sistema não adensado, $5.199 \mathrm{~kg} \mathrm{ha}^{-1}$, evidenciando-se favorecimento da produtividade com mais palha. Fica em destaque que o denominado sistema plantio direto praticado na região, sem preocupação com rotação de culturas e manutenção do solo coberto, não favorece a adubação antecipada. Por outro lado, as produtividades médias entre as épocas, independentemente do adensamento, foram de $4.758,5.860$ e $5.825 \mathrm{~kg} \mathrm{ha}^{-1}$, quando efetuados os primeiros parcelamentos de $\mathrm{N}$-fertilizante aos 59 e 21 dias antes da semeadura e aos 22 dias após a semeadura respectivamente. Com a aplicação do primeiro parcelamento, aos 21 dias antes da semeadura e, em cobertura tradicional, não foram constatadas diferenças significativas. Pode-se concluir que a atividade respiratória da biomassa microbiana não foi prejudicada pela aplicação de $\mathrm{N}$ em cobertura, nem pelo adensamento da palha, e somente pela condição de umedecimento do solo. Para solos sem preparo, e sem planejamento de rotação de culturas, visandose cobertura permanente, é mais conveniente a aplicação de $\mathrm{N}$ em cobertura tradicional, de forma parcelada, para obtenção de maiores valores de produtividade de milho.
\end{abstract}

Palavra-chave: solo sem preparo, N-foliar, evolução de $\mathrm{C}-\mathrm{CO}_{2}$, cobertura nitrogenada, época de aplicação $\mathrm{N}$-fertilizante.

$\left({ }^{1}\right)$ Recebido para publicação em 19 de janeiro de 2007 e aceito em 3 de maio de 2008.

$\left({ }^{2}\right)$ Pólo Regional Noroeste Paulista - Votuporanga, DDD/APTA/SAA, Caixa Postal 61, 15500-970 Votuporanga (SP). E-mail: waldolar@apta.sp.gov.br $\left(^{*}\right)$ Autor correspondente. 


\title{
ABSTRACT \\ SOIL MICROBIAL ACTIVITY AND PRODUCTIVITY OF MAIZE IN FUNCTION OF IMPLEMENTATION OF EARLY NITROGEN AND STRAW THICKNESS
}

\begin{abstract}
The climatic limitations in the Northwest region of São Paulo State, Brazil, ally to low altitudes, are limiting factors for the maize culture. The increase of the current productivities mainly depends on the handling, having to be improved the nitrogen fertilization. With this purpose an experiment was carried out at the Pólo Regional Noroeste Paulista, located in the Northwest region of São Paulo State, county of Votuporanga, State of São Paulo, using a moderate eutrofic Argissol, of sandy texture (100 g. $\mathrm{kg}^{-1}$ of clay), in order to evaluate the productivity of grains and the respiratory activity of the soil microbial biomass, when the nitrogen side-dressing was applied in anticipated form and in the traditional form, under two conditions of straw thickness. The statistical design was randomized blocks, in strips, for the times of fertilization and straw thickness. Ammonium sulphate was used as side-dress fertilization, applied twice for each time treatment, with 40 and $70 \mathrm{~kg}$.ha-1 of $\mathrm{N}$, applied in superficial band, in the space between the plant rows. The times of application were: a) 59 and 45 days before the sowing of maize, b) 21 and 6 days before sowing and c) in traditional side-dressing, 22 and 46 days after the sowing, in the respective stages V5 and V8, with three replications, under two conditions of straw thickness. Each plot had $50 \mathrm{~m}$ of length and $3,2 \mathrm{~m}$ of width, with four plant rows, with $0.8 \mathrm{~m}$ between the rows. The results showed an immediate response of the respiratory activity in function of the ground moisture, increasing the $\mathrm{C}-\mathrm{CO}_{2}$ evolution after the registered precipitation events at the three times of application of $\mathrm{N}$ in side-dressing. There was not a significant effect of the application of $\mathrm{N}$ in the respiratory activity of the ground biomass. The results showed that the no tillage system in this region, without considering crop rotation and keeping the ground coverage, does not favor the anticipated fertilization. On the other hand, the productivity averages for the times of application, independently of the straw thickness, were $4,758,5,860$ and 5,825 kg.ha-1 ${ }^{-1}$ for the first parcels of $\mathrm{N}$-fertilizer application at 59 and 21 days before sowing and 22 days after sowing, respectively. The application of the first parcel at 21 days before sowing and the traditional application 22 days after sowing did not show significant difference. It can be concluded that, the respiratory activity of the soil microbial biomass was not affected by the application of $\mathrm{N}$ in side-dressing nor for the thickness of the straw coverage and it was only affected by the ground moisture condition. For soils without preparation, without crop rotation, aiming at permanent soil coverage, the application of $\mathrm{N}$ in traditional side-dressing is more convenient, with splited applications to get higher maize productivity.
\end{abstract}

Key words: soil without preparation, foliar-N, evolution of $\mathrm{C}-\mathrm{CO}_{2}$, nitrogen side-dressing, time of application of $\mathrm{N}$-fertilizer.

\section{INTRODUÇÃO}

Na procura de aumentos de produtividade na cultura de milho, nos últimos anos vários trabalhos têm sido publicados, especialmente no sul do País, avaliando a adubação nitrogenada de cobertura de forma antecipada à semeadura de milho e o efeito de diferentes culturas antecessoras, manejadas em forma exclusiva ou consorciada (DA Ros et al., 2003, LARA Cabezas et al., 2004, Pottker e Wiethölter, 2004, ERnANi et al., 2005, DA Silva et al., 2005, DA Silva et al., 2006). Com essas práticas de manejo são afetados o comportamento da biomassa microbiana (GHOSHAL and Singh, 1995, Assis et al., 2003) e os processos de transformação bioquímica do N no solo (WANG et al., 2006), e conseqüentemente, sua disponibilidade.

A respiração microbiana representa a oxidação da matéria orgânica $(\mathrm{MO})$ por organismos aeróbios que utilizam $\mathrm{O}_{2}$ como aceptor de elétrons até $\mathrm{CO}_{2}$ (Moreira e Siqueira, 2002), constituindo um método prático para estimativa da quantidade de microorganismos vivos no solo (SANTOS e CAMARGo, 1999). A umidade, temperatura, aplicação de defensivos, metais pesados e a disponibilidade e degradação dos resíduos vegetais são fatores de influência na atividade respiratória, considerada como um indicador da condição ambiental (De-Polli e Guerra, 1997), apesar de elevado coeficiente de variação devido à variabilidade espacial (CONCEIção et al. 2005). Assis et al (2003), não verificaram influência da adubação nitrogenada, aplicada na dose de $30 \mathrm{~kg} \mathrm{ha}^{-1}$, na atividade respiratória da biomassa, em solo de cerrado. Esse fato pode ter ocorrido devido à pequena dose de $\mathrm{N}$ utilizada, à retenção do fertilizante na palha de sorgo ou à seleção de microorganismos para decomposição dos resíduos, nos primeiros 15 dias após a aplicação. PASSIANOTO et al. (2001), verificaram aumentos crescentes na atividade respiratória após 140 dias da aplicação de dois tipos de esgotos, sendo a fonte energética de carbono (C) requerida para tal aumento. De forma similar, Ghoshal and Singh (1995), aplicando fertilizante mineral, esterco e esterco + fertilizante 
mineral constataram valores médios de 245, 305 e 365 $\mathrm{mg} \mathrm{g} \mathrm{g}^{-1}$ de biomassa-C, e ativação da biomassa pela fonte de C associada ao fertilizante. JonAsson et al. (1996), aplicando glicose e fertilizante NPK dentre outros tratamentos, obtiveram aumento de $15 \%$ a $37 \%$ na biomassa-C, com a aplicação exclusiva de glicose, sem aumento na assimilação de N. Por sua vez, com a aplicação da fonte NPK não foi afetada a quantidade de biomassa-C, a biomassa-N foi aumentada significativamente e os nutrientes fornecidos imobilizados. CHen and Hughes (2002), aplicando zero, 300 e $600 \mathrm{~kg} \mathrm{ha}^{-1}$ de nitrato de amônio em solo de floresta de araucária na Austrália, verificaram, após cinco anos, aumento significativo nas taxas de mineralização-imobilização bruta com o tratamento de $600 \mathrm{~kg} \mathrm{ha}^{-1}$, sem que fossem significativamente afetadas as concentrações de $\mathrm{C}$ e $\mathrm{N}$ total de solo. Aparentemente, houve diminuição da biomassa-C e $-\mathrm{N}$ e respiração microbiana, aumentando o quociente metabólico $\left(\mathrm{C}-\mathrm{CO}_{2} /\right.$ biomassa). SАКАмото е Ова (1994), sugerem ser a relação biomassa fungo/bactéria um importe regulador da relação entre $\mathrm{CO}_{2}$ evoluído e tamanho da biomassa. Portanto, um aumento no quociente metabólico, como o registrado por CHEN and Hughes (2002), seria devido à maior proporção de bactérias que de fungos na biomassa, com menos eficiência no uso do substrato de C.

Em relação à prática de adubação nitrogenada antecipada à semeadura, DA Ros et al. (2003), verificaram que, somente com o parcelamento de $\mathrm{N}$ à semeadura e o restante em cobertura foi aumentada a disponibilidade de $\mathrm{N}$ no solo nos estádios de mais demanda pelas culturas de milho e trigo. A produção de massa de matéria seca (MMS), o $\mathrm{N}$ acumulado na planta e a produtividade não foram afetados pela antecipação da adubação nitrogenada. PÖTtKer e WiETHÖLTER (2004) não constataram diferenças de aplicação entre a semeadura e a cobertura, entretanto, na ocorrência de elevada precipitação pluvial, com a aplicação de $\mathrm{N}$ em cobertura houve rendimentos maiores de milho. Maiores valores de produtividades em milho foram obtidos com cobertura tradicional em Palmital (SP), em solo argiloso e em Votuporanga (SP), em solo arenoso, quando comparado com a aplicação de $\mathrm{N}$ cerca de um mês antes da semeadura (Cantarella et al., 2005). Em Montividiu (GO), DA SILVA et al. (2005), aplicando $\mathrm{N}$ em pré-semeadura, aos 15 e 35 dias após a emergência, verificaram ser desfavorável essa prática para as condições edafoclimáticas do local. No caso de aplicação de N parcelado em pós-semeadura, YANO et al (2005), aplicando $\mathrm{N}$ a lanço em três épocas, logo após a semeadura, no perfilhamento e no emborrachamento da cultura de milho, não verificaram diferenças significativas entre os tratamentos; a melhoria foi somente na qualidade protéica nos grãos com os parcelamentos. Com a aplicação em cobertura tradicional asseguram-se incrementos significativos no rendimento de milho, independentemente da precipitação pluvial ser normal ou excessiva (KLuthCouski et al., 2006). Há registro na literatura mostrando ser favorável a antecipação no Sul do país (BAsso et al., 1998). Segundo CoElHo et al (2003), na aplicação de parte do $\mathrm{N}$ em pré-semeadura há algumas vantagens operacionais, como mais flexibilidade no período de execução da adubação e a racionalização no uso de maquinário e mão-de-obra. Entretanto, devido à complexidade na dinâmica do $\mathrm{N}$ condicionada aos fatores ambientais, não se pode fazer generalização dessa prática, principalmente com o uso de uréia. Segundo KLUTHCouski et al. (2006), somente em solos sob sistema plantio direto (SPD) estabelecido, com aporte contínuo de palha e teor adequado de $\mathrm{MO}$, a adubação nitrogenada pode ser antecipada, em anos com chuvas regulares. Isto seria factível em solos férteis no cerrado, onde não há probabilidade de chuvas intensas em pré-semeadura.

Na Região Noroeste paulista, o milho é cultivado pela grande maioria de pequenos e médios produtores, dispondo-se de informações de manejo importadas de outras localidades para melhorar a produtividade. Portanto, este estudo, objetivou avaliar a produtividade de grãos e a atividade respiratória da biomassa microbiana, quando efetuada a cobertura nitrogenada de forma antecipada à semeadura e de forma tradicional, sob duas condições de cobertura de palha em argissolo de textura arenosa.

\section{MATERIAL E MÉTODOS}

O experimento foi desenvolvido no Pólo Regional Noroeste Paulista, rodovia municipal Votuporanga-Nhandeara, $\mathrm{km} \mathrm{4}$, município de Votuporanga (SP), entre agosto de 2005 e maio de 2006, em Argissolo Vermelho, eutrófico, A moderado, textura arenoso-média, teor de argila de $100 \mathrm{~g} \mathrm{~kg}^{-1}$ na camada de $0-25 \mathrm{~cm}$ (EMBRAPA, 1999). A caracterização química do solo, na camada de 0 a $20 \mathrm{~cm}$ foi: $\mathrm{pH}$ $\left(\mathrm{CaCl}_{2}\right)$ 5,8; P (resina) $33 \mathrm{mg} \mathrm{dm}^{-3} ; 1,4,26,0$ e 9,0 mmol $_{\mathrm{c}}$ $\mathrm{dm}^{-3}$ de $\mathrm{K}, \mathrm{Ca}$ e $\mathrm{Mg}$, respectivamente; CTC efetiva de $51,4 \mathrm{mmol}_{\mathrm{C}} \mathrm{dm}^{-3} ; 71 \%$ de saturação por bases e $12 \mathrm{~g}$ $\mathrm{dm}^{-3}$ de MO. A amostragem de solo foi efetuada em abril de 2005, sendo coletadas 15 amostras simples de forma aleatória na área experimental para composição de uma amostra. Na safra de 2003/2004, a área fora cultivada em solo sem preparo, com soja variedade IAC-18, produtividade média de $2.500 \mathrm{~kg}$ $\mathrm{ha}^{-1}$ e em 2004/2005, com milho variedade ALPiratininga, produtividade de $2.500 \mathrm{~kg} \mathrm{ha}^{-1}$, sendo afetado este último por severo veranico. 
Nas entressafras, a área permaneceu em pousio, com crescimento de vegetação espontânea composta principalmente de plantas daninhas.

Em agosto de 2005, foram instalados dois tratamentos de adensamento de palha, utilizando-se a própria vegetação espontânea do local (resíduos vivos e mortos de culturas antecessoras e plantas daninhas), ficando as quantidades médias, iguais a $5.120 \mathrm{~kg} \mathrm{ha}^{-1} \mathrm{em}$ área mais adensada e $3.648 \mathrm{~kg} \mathrm{ha}^{-1}$ em área com menor adensamento. Para estimarem-se os valores, foram coletadas seis amostras de massa de matéria verde com quadrante de $1 \mathrm{~m}^{2}$ e determinada a MMS, colocando a secar o material em estufa com ar forçado a $60^{\circ} \mathrm{C}$ até massa constante, expressa em kg ha-1. Posteriormente, em 31/10/2005 e 24/1/2006 foram realizadas duas amostragens, para se avaliar a decomposição do material ao longo do tempo.

Previamente à semeadura do milho, em 26/ $10 / 2005$ e 12/11/2005, foi efetuado o dessecamento seqüencial na área, aplicando-se $2 \mathrm{~L} \mathrm{ha}^{-1}$ de glifosate $+1 \mathrm{~L} \mathrm{ha}^{-1}$ de 2,4 -D na primeira e exclusivamente $1 \mathrm{~L}$ $\mathrm{ha}^{-1}$ de glifosate na segunda aplicação. O híbrido simples, 30-F35 (Pionner), precoce, foi semeado em 20/ $12 / 2005$, no espaçamento entrelinhas de $0,8 \mathrm{~m}$, e densidade de 62.000 sementes por hectare. No sulco de semeadura, nos tratamentos descritos a seguir, realizou-se a aplicação de 30, 104 e $59 \mathrm{~kg} \mathrm{ha}^{-1}$ de N, $\mathrm{P}_{2} \mathrm{O}_{5}$ e $\mathrm{K}_{2} \mathrm{O}$, nas formas de MAP; sulfato de amônio; formulações 15:06:00; 04:14:08 e 03:17:00; $\mathrm{KCl}$ e 150 $\mathrm{g} \mathrm{kg}^{-1}$ de Zn granulado.

O experimento foi instalado em delineamento de blocos casualizados, em esquema de faixas, para as épocas de adubação em cobertura e o adensamento de palha, com três repetições. Na cobertura nitrogenada foi utilizado sulfato de amônio, parcelado em duas vezes, em doses de 70 e $40 \mathrm{~kg} \mathrm{ha}^{-1}$ de N, aplicado em faixa superficial, na entrelinha. As épocas de aplicação foram aos 59 e 45 dias antes da semeadura de milho, aos 21 e seis dias antes da semeadura e em cobertura tradicional, aos 22 e 46 dias após a semeadura, nos estágios respectivos V5 e V8. Cada parcela ficou constituída de $50 \mathrm{~m}$ de comprimento e $3,2 \mathrm{~m}$ de largura, contendo quatro fileiras de plantas, com espaçamento de $0,8 \mathrm{~m}$ entre as linhas. Foram executados os tratos culturais de controle de pragas e plantas daninhas adequados para a região.

\section{Atividade respiratória da biomassa microbiana}

A atividade respiratória de $\mathrm{C}-\mathrm{CO}_{2}$ evoluído foi determinada somente no primeiro parcelamento de adubação em cobertura para cada tratamento, segundo procedimento adaptado de Araújo (2002). Sete unidades coletoras de $\mathrm{C}-\mathrm{CO}_{2}$ foram instaladas acima da faixa de adubo aplicado, em duas das três repetições de cada tratamento. Como testemunhas, foram instaladas seis unidades sobre solo não adubado, nas duas condições de palha. Cada unidade foi composta de um frasco contendo $50 \mathrm{~g}$ de solução $1 \mathrm{~mol} \mathrm{~L}^{-1}$ de $\mathrm{NaOH}$, coberta com tela de galinheiro para se evitar a entrada de insetos. Os frascos foram protegidos no interior de anéis de PVC de $20 \mathrm{~cm}$ de diâmetro, sendo considerada a área de emissão de C$\mathrm{CO}_{2}$ para os efeitos de cálculo. À coleta, foi adicionado $1 \mathrm{~mL}$ de solução de $\mathrm{BaCL}_{2}$ em cada amostra, para precipitar o $\mathrm{CO}_{2}$ capturado na forma de carbonato de bário. Em cada tratamento, foram realizadas três amostragens consecutivas, com troca dos frascos a intervalos de no mínimo 48 horas. A comparação das médias de $\mathrm{C}-\mathrm{CO}_{2}$ evoluído entre os tratamentos para cada intervalo de amostragem, foi efetuada por análise de variância em blocos casualizados, aplicando-se o teste de Tukey ao nível de 0,05. Na instalação das unidades e a cada coleta, foi realizada amostragem de solo da camada superficial de 0 a $10 \mathrm{~cm}$, para a determinação de umidade com base em MMS pelo método gravimétrico.

\section{Diagnose foliar de $\mathrm{N}$ e produtividade de grãos}

Em 24/1/2006, na época de florescimento pleno, foi efetuada amostragem foliar para diagnose de N. Foram coletadas as folhas opostas e abaixo da espiga em 10 plantas de cada repetição por tratamento, segundo preconizado por MaLAVolta et al. (1997). A avaliação nutricional foi efetuada no Laboratório Unithal, em Campinas (SP).

Em 4/5/2006 foi realizada a colheita de grãos para determinação da produtividade. Em cada repetição foram contadas as plantas totais (sem e com espigas), e as efetivas (com espigas), em três fileiras de $15 \mathrm{~m}$ cada, para a determinação da porcentagem de redução de produtividade devido às plantas dominadas. De cada fileira foram colhidas as espigas com palha para composição de uma amostra, que foram pesadas e debulhadas, sendo determinada a umidade com medidor universal e posterior correção do peso a $130 \mathrm{~g} \mathrm{~kg}^{-1}$. Amostras de grãos de cada tratamento foram secas em estufa a $60{ }^{\circ} \mathrm{C}$ até massa constante, para a determinação da concentração de macronutrientes $\mathrm{N}$, $\mathrm{P}, \mathrm{K}$ e $\mathrm{S}$ no Laboratório Unithal em Campinas-SP. Também, em cada parcela, foram coletadas as plantas inteiras, sem as espigas, em 1 metro linear a $10 \mathrm{~cm}$ da superfície do solo, para a determinação da MMS da parte aérea. O material foi triturado, homogeneizado e subamostrado para secagem em estufa com ar forçado como indicado anteriormente. 
A comparação das médias de produtividade e da concentração de nutrientes nos grãos foi determinada por análise de variância em esquema fatorial $3 \times 2$ (aplicação de $\mathrm{N}$ em três épocas, sob duas condições de adensamento da palha), aplicando-se o teste de Tukey ao nível de 0,05 . O teste de $t$ (Students) foi utilizado ao nível de 0,05 para a comparação de médias de MMS da palha residual de milho, entre os tratamentos.

Durante o período experimental, entre outubro de 2005 e maio de 2006 foi feito acompanhamento da pluviosidade no local experimental.

\section{RESULTADOS E DISCUSSÃO}

Na figura 1, verifica-se a distribuição da pluviosidade durante o período experimental. Devido à demora na regularização da precipitação pluvial, foi obrigatório o adiamento da semeadura para dezembro de 2005, sendo provavelmente prejudicada a produtividade. FORSTHOFER et al. (2006), avaliando a semeadura de milho em agosto, outubro e dezembro no Rio Grande do Sul, com três níveis de tecnologia, para cada época, não verificaram retorno econômico na semeadura efetuada em dezembro (tardia), com utilização de sistemas de manejo destinados à potencialização do rendimento de grãos. Entretanto, na semeadura em outubro, foram favorecidos o maior acúmulo de carboidratos, o número de grãos por $\mathrm{m}^{2}$ e a produtividade. Ainda, devido a um veranico prolongado em janeiro de 2006 e à semeadura tardia, a produtividade de milho deve ter sido negativamente afetada.

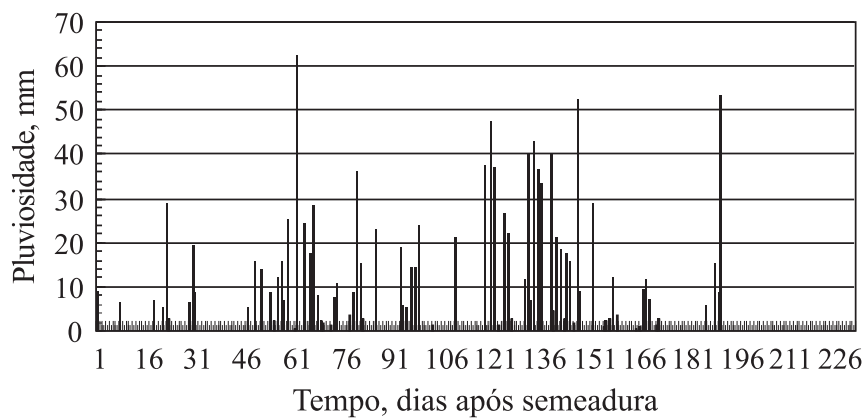

Figura 1. Distribuição diária da pluviosidade na área experimental entre os meses de outubro de 2005 até maio de 2006 (Votuporanga, SP).

Em relação às coberturas mortas instaladas em agosto de 2005, foram determinados 5.120 e $3.648 \mathrm{~kg}$ $\mathrm{ha}^{-1}$ em área adensada e não adensada respectivamente. Posteriormente, em 31/10/2005, as MMS determinadas em ambas as áreas foram similares, $6.886 \mathrm{~kg} \mathrm{ha}^{-1}$ e $6.688 \mathrm{~kg} \mathrm{ha}^{-1}$ respectivamente. Houve desenvolvimento da vegetação espontânea nesse período, sendo mais expressivo em área não adensada. TREZZI e VIDAL (2004) verificaram que $4 \mathrm{t} \mathrm{ha}^{-1}$ de palha de sorgo ou milheto foram suficientes para a redução de $91 \%, 96 \%$ e $59 \%$ da população total de Brachiaria plantaginea, Sida rhombifolia e Bidens pilosa, respectivamente, sendo resíduos da parte aérea de sorgo importantes na supressão de plantas daninhas. Neste estudo, os resultados poderiam ser explicados pela inibição do crescimento da vegetação espontânea pela maior cobertura de solo. Após 84 dias de efetuada a estimativa, em 24/1/2006, na área adensada havia, em média, $4.178 \mathrm{~kg} \mathrm{ha}^{-1}$ de MMS e, na não adensada, $2.380 \mathrm{~kg} \mathrm{ha}^{-1}$ de MMS, valores representativos de uma taxa média de decomposição nesse intervalo de tempo de 32,2 e $51,3 \mathrm{~kg} \mathrm{ha}^{-1} \mathrm{dia}^{-1}$ respectivamente. A maior proporção de material vegetativo vivo na área não adensada foi, provavelmente, decomposto mais rapidamente devido ao dessecamento realizado em pré-semeadura de milho, bem como na área com mais adensamento, o material deve ter sido mais resistente à decomposição, representado pela menor taxa calculada.

\section{Atividade respiratória da biomassa microbiana}

Nas figuras 2, 3 e 4 são apresentados os resultados de respirometria determinados nas três épocas de aplicação da primeira parcela de cobertura nitrogenada antecipada aos 59 e 21 dias antes da semeadura, e na cobertura tradicional, aos 22 dias após a semeadura. Em cada figura foram incluídos os dados de pluviosidade e umidade do solo da camada de 0-20 cm, para cada época.

A pluviosidade entre os dias 19 a 26 de outubro de 2005 foi de $36,8 \mathrm{~mm}$ (Figura 2a) e entre os dias 19 a 21 de outubro foi de $5,2 \mathrm{~mm}$, com valores de $\mathrm{C}-\mathrm{CO}_{2}$ acumulados de 56,5 e $55,3 \mathrm{mg} \mathrm{m}^{-2} \mathrm{~h}^{-1}$, respectivamente, na área sem e com adensamento (Figura 2b). No segundo intervalo, entre 21 e 24 de outubro, foram registrados $31,6 \mathrm{~mm}$, com aumentos significativos na atividade respiratória: 65,1 e $71,1 \mathrm{mg}$ $\mathrm{m}^{-2} \mathrm{~h}^{-1}$, nos tratamentos sem e com adensamento respectivamente. No último intervalo não se registrou precipitação pluvial e ocorreu redução apreciável da atividade respiratória em ambos os tratamentos de adensamento. Houve acréscimo no teor de água no solo de aproximadamente $40 \mathrm{~g} \mathrm{~kg}^{-1}$ depois da pluviosidade, entre os dias 24 e 26 de outubro. LiRA et al. (1999) também avaliaram aumentos na respiração no início do verão, por ocasião do início das chuvas, em relação ao inverno, sendo variável de 40-50 mg m $\mathrm{hr}^{-1}$ a $100-110 \mathrm{mg} \mathrm{m}^{-2} \mathrm{hr}^{-1}$, respectivamente. 

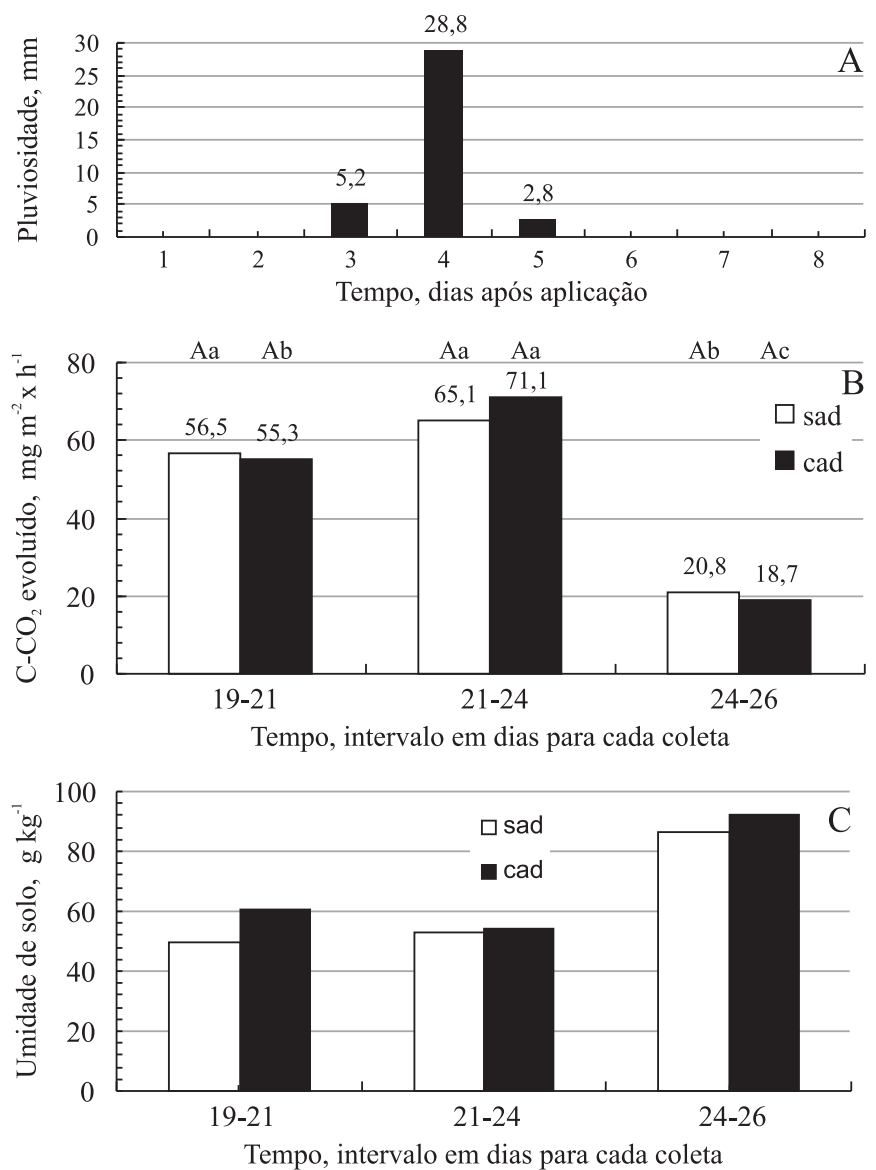

Figura 2. Distribuição da precipitação pluvial em outubro de 2005 (a), respirometria de $\mathrm{C}-\mathrm{CO}_{2}$ da biomassa (b) e grau de umidade do solo (c) aos 59 dias antes da semeadura de milho, após o primeiro parcelamento de cobertura nitrogenada antecipada, sem (sad) e com adensamento de palha (cad). Adensado: $5.120 \mathrm{~kg} \mathrm{ha}^{-1}$ de massa de matéria seca de cobertura de solo e não adensado: $3.648 \mathrm{~kg} \mathrm{ha}^{-1}$.

Em b), entre adensamentos de palha, as médias seguidas de letras maiúsculas desiguais, são diferentes significativamente entre si, pelo teste de Tukey ao nível de 0,05 .

Em b), entre intervalos de tempo, as médias seguidas de letras minúsculas desiguais, são diferentes significativamente entre si, pelo teste de Tukey ao nível de 0,05.

DMS(entre adensamentos) $=8,5 ;$ DMS(entre intervalos de tempo $)=10,3 ; \mathrm{CV}(\%)=23,6$

Na figura 3 está apresentada a atividade respiratória microbiana registrada entre os dias 28 de novembro a oito de dezembro de 2005, quando foi efetuado o primeiro parcelamento da segunda adubação em pré-semeadura, aos 21 dias antes da semeadura de milho, nos dois tratamentos de adensamento de palha. Nesse período, a pluviosidade foi regular (Figura 3a), com pico de atividade respiratória em resposta à intensa pluviosidade, entre os dias dois a seis de dezembro de 2005 (Figura 3b), e valores médios acumulados de $100,0 \mathrm{mg} \mathrm{m}^{-2} \mathrm{~h}^{-1} \mathrm{e}$ 93,2 $\mathrm{mg} \mathrm{m}^{-2} \mathrm{~h}^{-1}$ de C-CO $\mathrm{CO}_{2}$ evoluído, nas áreas sem e com adensamento respectivamente. Também, para cada intervalo de medida, não houve diferença significativa devido aos adensamentos de palha. A posterior diminuição da pluviosidade foi relacionada com as correspondentes diminuições na umidade de solo (Figura 3c) e na respiração (Figura 3b).
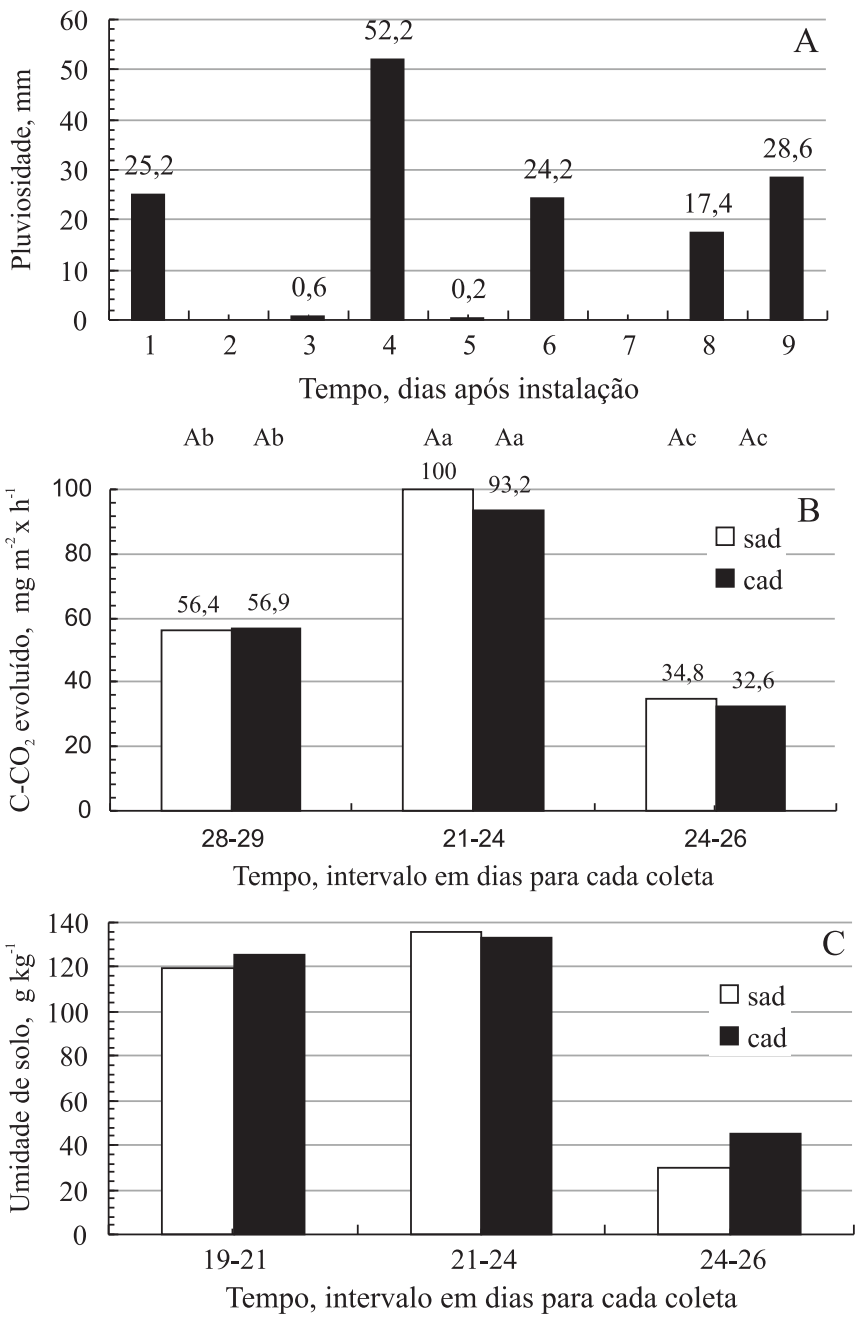

Figura 3. Distribuição da precipitação pluvial em novembro e dezembro de 2005 (a), respirometria de $\mathrm{C}-\mathrm{CO}_{2}$ da biomassa (b) e grau de umidade do solo (c) aos 21 dias antes da semeadura de milho, após o primeiro parcelamento de cobertura nitrogenada antecipada, sem (sad) e com adensamento de palha (cad). Adensado: $5.120 \mathrm{~kg} \mathrm{ha}^{-1}$ de massa de matéria seca de cobertura de solo e não adensado: $3.648 \mathrm{~kg} \mathrm{ha}^{-1}$.

Em b), entre adensamentos de palha, as médias seguidas de letras maiúsculas iguais, não são diferentes significativamente entre si, pelo teste de Tukey ao nível de 0,05.

Em b), entre intervalos de tempo, as médias seguidas de letras minúsculas iguais, não são diferentes significativamente entre si, pelo teste de Tukey ao nível de 0,05.

DMS(entre adensamentos) $=9,3$; DMS(entre intervalos de tempo $)=11,2 ; C V(\%)=19,9$ 
Na figura 4 consta a distribuição da precipitação pluvial, a atividade respiratória e a umidade de solo registradas entre os dias 13 e 27 de janeiro de 2006, após a aplicação do primeiro parcelamento em cobertura nitrogenada tradicional de milho. Diferentemente das épocas anteriores, ocorreu veranico pronunciado antes da determinação da atividade respiratória e na ausência de umidade adequada no solo, a evolução de $\mathrm{C}-\mathrm{CO}_{2}$ foi mantida em valores inferiores a $35 \mathrm{mg} \mathrm{m}^{-2} \mathrm{~h}^{-1}$, nos três intervalos de tempos (Figura 4b).
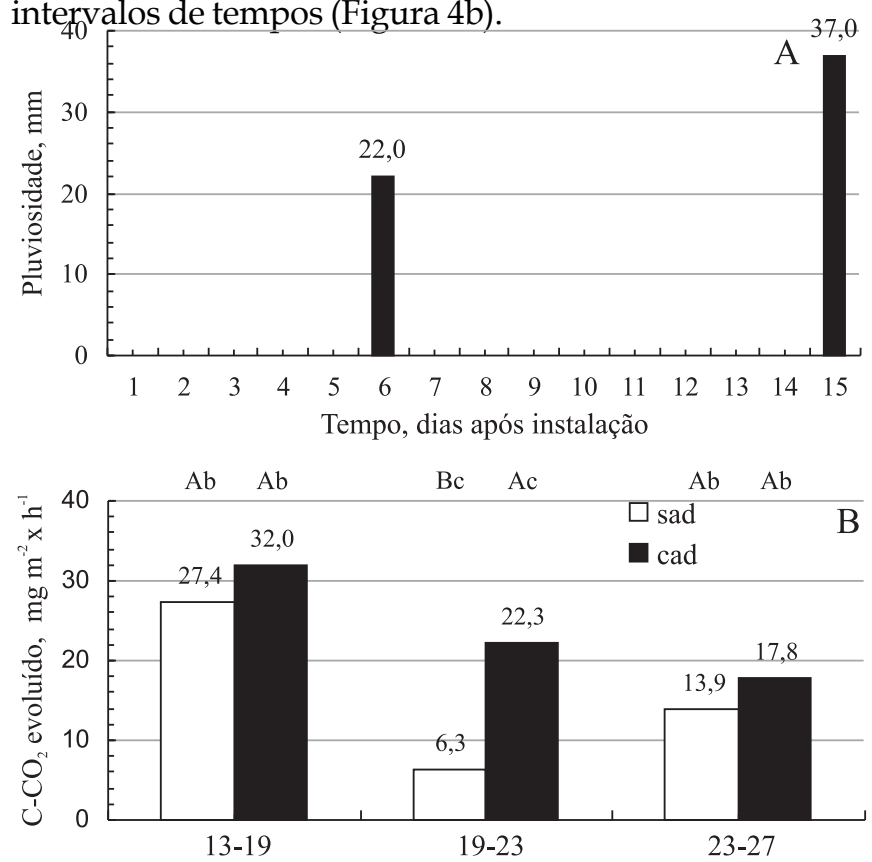

Tempo, intervalo em dias para cada coleta

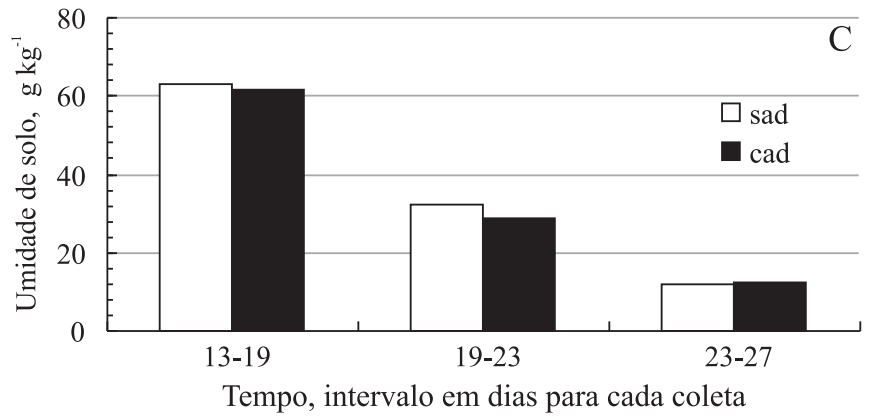

Figura 4. Distribuição da precipitação pluvial em janeiro de 2006 (a), respirometria de $\mathrm{C}-\mathrm{CO}_{2}$ da biomassa (b) e grau de umidade do solo (c) aos 22 dias após a semeadura de milho, no primeiro parcelamento de cobertura nitrogenada antecipada, sem (sad) e com adensamento de palha (cad). Adensado: $5.120 \mathrm{~kg} \mathrm{ha}^{-1}$ de massa de matéria seca de cobertura de solo e não adensado: $3.648 \mathrm{~kg} \mathrm{ha}^{-1}$.

Em b), entre adensamentos de palha, as médias seguidas de letras maiúsculas desiguais, são diferentes significativamente entre si, pelo teste de Tukey ao nível de 0,05 .

Em b), entre intervalos de tempo, as médias seguidas de letras minúsculas desiguais, são diferentes significativamente entre si, pelo teste de Tukey ao nível de 0,05.

DMS(entre adensamentos) $=5,0 ;$ DMS(entre intervalos de tempo $)=6,0 ; C V(\%)=33,3$
EsPíndolA et al (2001), em área da Baixada Fluminense, determinaram a respiração microbiana de forma sazonal, registrando valores de 224,7, 152,7, 154,0, 175,2 e $216,9 \mathrm{mg} \mathrm{kg}^{-1}$ de C-CO $\mathrm{CO}_{2}$ no verão, outono, inverno e primavera de 1994, e no verão de 1995 respectivamente. Nos resultados foi mostrada, em termos de tendência, mais atividade respiratória em solo com adensamento que em solo sem adensamento de palha. Provavelmente, com mais retenção de umidade no solo, devido ao adensamento de palha (TORMENA et al., 2004), tenha havido contribuição para o aumento da atividade.

Na figura 5, verificam-se os valores médios de atividade respiratória da biomassa microbiana, determinada após as três épocas de cobertura nitrogenada, em ausência e presença do fertilizante aplicado na cobertura nitrogenada, independentemente do adensamento de palha de cobertura. Os valores mais elevados foram obtidos na ocorrência de maior umidade, entre de outubro e dezembro de 2005. Em janeiro de 2006, devido ao veranico mencionado, houve uma redução importante na atividade respiratória. Conforme os resultados em cada época, não houve efeito da adubação nitrogenada. Em princípio, como afirmam MoreIRA e Siqueira (2002), com a aplicação de $\mathrm{N}$ haveria mais consumo pela biomassa e consequiente liberação de $\mathrm{CO}_{2}$. Entretanto, em estudo realizado por Assis et al. (2003), verificou-se não haver influência na atividade respiratória, após 15 dias da aplicação de 30 kg.ha-1 de $\mathrm{N}$ sobre palhada de sorgo.

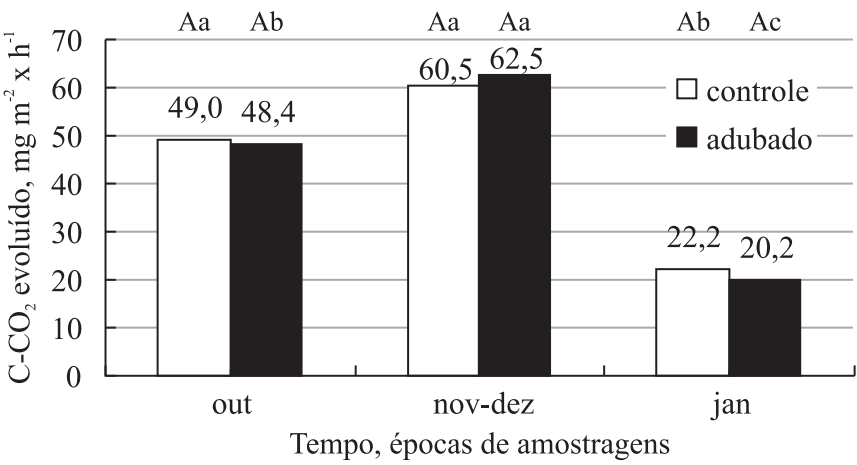

Figura 5. Atividade respiratória média da biomassa microbiana determinada após a aplicação do primeiro parcelamento de cobertura nitrogenada aos 59 e 21 dias antes da semeadura de milho e aos 22 dias após a semeadura, independentemente do adensamento de cobertura de palha, em relação à ausência de adubação nitrogenada em cobertura, na safra 2005/2006. Votuporanga (SP).

Entre tratamentos sem e com adubação em cobertura de $\mathrm{N}$, as médias seguidas de letras maiúsculas iguais, não são diferentes significativamente entre si, pelo teste de Tukey ao nível de 0,05.

Entre épocas, as médias seguidas de letras minúsculas iguais, não são diferentes significativamente pelo teste de Tukey ao nível de 0,05.

DMS(entre tratamentos de adubação) $=27,1$; DMS(entre épocas) $=32,60 ; \mathrm{CV}(\%)=52,33$. 
PAssianoto et al. (2001), verificaram aumentos crescentes na atividade respiratória após 140 dias da aplicação de lodos contendo metal pesado. GHOSHAL and SINGH (1995) determinaram aumento na atividade respiratória quando aplicaram mistura de lodo como fonte de $\mathrm{C}$ e fertilizante, sendo superior à aplicação exclusiva de fertilizante.

No estudo realizado, o reduzido teor de $\mathrm{MO}$ no solo, com aplicação em superfície de sulfato de amônio e reduzidos teores de $\mathrm{C}$ e de argila, são fatores de possível dificuldade à relação de $\mathrm{N}$ aplicado e seu efeito na atividade respiratória da biomassa. Ainda, nesse solo, deve haver limitação da quantidade de biomassa.

$\mathrm{Na}$ época de pleno florescimento foi avaliado o teor foliar de N, como mostrado na figura 6 , nas três épocas de aplicação de $\mathrm{N}$, nas duas condições de adensamento de palha. Os teores médios de $\mathrm{N}$ foliar nas condições de menos e mais adensamento de palha foram 32,4 e $31,8 \mathrm{~g} \mathrm{~kg}^{-1}$ respectivamente, independentemente das épocas de aplicação de $\mathrm{N}$ em cobertura, não havendo, portanto, efeito do adensamento.

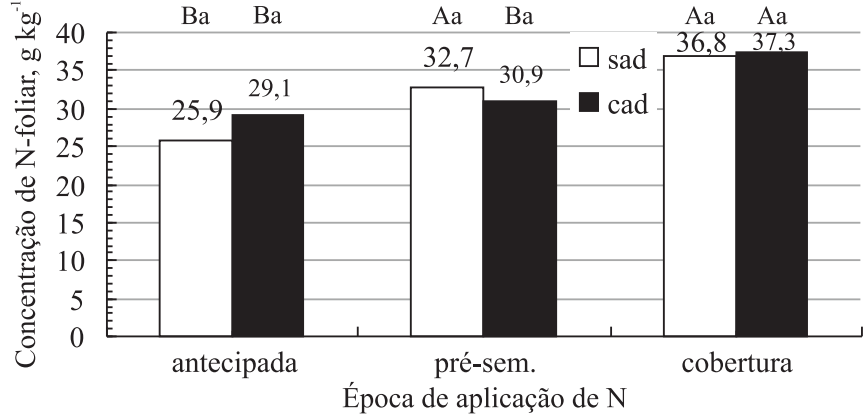

Figura 6. Concentração de N-foliar na cultura de milho em função da época de aplicação de $\mathrm{N}$ em cobertura, em duas condições de adensamento de palha, safra 2005/2006, Votuporanga (SP). Adensado: $5.120 \mathrm{~kg} \mathrm{ha}^{-1}$ de massa de matéria seca de cobertura de solo e não adensado: $3.648 \mathrm{~kg}$ ha 1. Antecipada $=59$ d.a.s; Pré-sem. $=21$ d.a.s. e Cobertura $=22$ d.após $\mathrm{s}$.

Entre épocas, as médias seguidas de letras maiúsculas iguais, não são diferentes significativamente entre si, pelo teste de Tukey ao nível de 0,05.

Entre adensamentos de palha, as médias seguidas de letras minúsculas iguais, não são diferentes significativamente entre si, pelo teste de Tukey ao nível de 0,05.

DMS(entre épocas) $=3,6$. DMS(entre adensamentos) $=2,4$; $\mathrm{CV}(\%)=7,3$
Indiretamente, essa avaliação é indicativa de mais acúmulo de $\mathrm{N}$ do fertilizante e do solo por unidade de MMS, em cobertura tradicional, independentemente da condição de cobertura morta no solo. A produtividade de grãos foi afetada negativamente em estudo realizado por DA SILVA et al. (2005), em Montividiu (GO), com a aplicação efetuada aos 20 dias antes da semeadura. Em Ribeirão Preto (SP), CANTARELLA et al (2003), utilizando a técnica de diluição isotópica $\operatorname{com}{ }^{15} \mathrm{~N}$, obtiveram mais recuperação de $\mathrm{N}$-uréia pelo milho em cobertura tradicional $(66,4 \%$ do $\mathrm{N}$-aplicado) em relação à aplicação antecipada (48,3 \%) na safra 1999/2000, sendo obtido um resultado semelhante na safra seguinte.

Na tabela 1 pode-se observar os valores de população de plantas por ocasião da colheita, as plantas efetivas (com espigas) e o percentual de cálculo de plantas sem espigas, para as três épocas de aplicação da adubação nitrogenada em cobertura, nos dois adensamentos de palha. Se a população de plantas projetada tivesse sido de 50.000 plantas ha ${ }^{-1}$, os resultados teriam sido satisfatórios para a população de plantas efetivas determinadas. Entretanto, houve uma diferença de aproximadamente 10.000 plantas por hectare a menos em relação ao estande de semeadura (62.000 sementes por ha $\left.{ }^{-1}\right)$, afetando em $16 \%$ a produção de espigas. Essa perda foi significativa, com o que, somada aos fatores climáticos adversos comentados, pode-se explicar a reduzida produtividade alcançada.

Em híbridos mais precoces, como o utilizado neste estudo, é requerida mais densidade de plantas em relação aos de ciclo normal para que o potencial de rendimento seja atingido. Isso se deve ao fato de os híbridos mais precoces geralmente terem menor estatura, folhas menores, menor área foliar por planta e menos sombreamento do dossel da cultura (ARGENTA et al., 2001). Neste caso pode-se aventar algum problema de calibração de maquinário, na medida em que a variação na população de plantas projetadas e efetivas foi mínima e bastante uniforme entre os tratamentos.

Na colheita de 4/5/2006 determinou-se a MMS na parte aérea de plantas, excluídas as espigas com palha em cada situação de adensamento, independentemente dos tratamentos de épocas de $\mathrm{N}$ aplicado. Em média, em nove amostragens efetuadas em cada local, 4.150 e $4.322 \mathrm{~kg} \mathrm{ha}^{-1}$ de MMS foram determinados nos tratamentos com menos e mais adensamento, respectivamente, não havendo sido constatada diferença significativa pelo teste de $\mathrm{t}$ (Student) ao nível de 0,05 de significância. 
Tabela 1. População de plantas totais (sem e com espigas) e efetivas (com espigas), e percentual de perda na época da colheita, em cultura de milho submetida a três épocas de aplicação de N, na safra 2005/2006, sob duas condições de adensamento de cobertura morta, em Votuporanga (SP) $\left({ }^{1}\right)$

\begin{tabular}{llccc}
\hline Época & Manejo da & Plantas totais & Plantas efetivas & Plantas sem espigas \\
& & & \\
& cobertura morta $\left({ }^{2}\right)$ & número ha ${ }^{-1}$ & & \\
& adensado & $51.389 \mathrm{Aa}$ & $48.796 \mathrm{Aa}$ & 5,0 \\
59 d.a.s. $\left({ }^{3}\right)$ & não adensado & $53.704 \mathrm{Aab}$ & $51.574 \mathrm{Aab}$ & 4,0 \\
& adensado & $53.519 \mathrm{Aa}$ & $51.204 \mathrm{Aa}$ & 4,3 \\
21 d.a.s. & não adensado & $55.408 \mathrm{Aa}$ & $54.445 \mathrm{Aa}$ & 1,7 \\
cobertura & adensado & $51.667 \mathrm{Aa}$ & $51.481 \mathrm{Aa}$ & 0,4 \\
tradicional & não adensado & $50.093 \mathrm{Ab}$ & $47.963 \mathrm{Ab}$ & 4,3 \\
DMS (entre épocas) & - & 4.916 & 5.766 & - \\
DMS (entre adensamentos) & - & 4.016 & 4.711 & - \\
CV (\%) & - & 4,3 & 5,2 & - \\
\hline
\end{tabular}

( ${ }^{1}$ ) Para plantas totais e efetivas, entre adensamentos para cada época, as médias seguidas de letras maiúsculas iguais, não são diferentes significativamente entre si pelo teste de Tukey ao nível de 0,05. Entre épocas, dentro de cada adensamento, as médias seguidas de letras minúsculas iguais, não são diferentes significativamente entre si pelo teste de Tukey ao nível de 0,05.

$\left.{ }^{2}\right)$ Adensado: $5.120 \mathrm{~kg} \mathrm{ha}^{-1}$ de massa de matéria seca de cobertura de solo e não adensado: $3.648 \mathrm{~kg} \mathrm{ha}^{-1}$.

$\left({ }^{3}\right)$ d.a.s. $=$ dias após semeadura

Na tabela 2 estão listados os resultados de produtividade de grãos e seus respectivos teores em N, P, K e S. Em relação ao híbrido utilizado, os resultados de produtividade, variáveis de $4.561 \mathrm{~kg}^{-1}$ a $6.241 \mathrm{~kg} \mathrm{ha}^{-1}$, podem ser considerados precários. A diferença entre o estande de plantas programado $\left(62.000\right.$ plantas ha $\left.^{-1}\right)$, e o efetivo (50.911 plantas ha-1, Tabela 1), afetou a produtividade, devido muito provavelmente à calibração de maquinário, mais que um problema de caráter fitossanitário (AlBUQUERQUE et al. 2006), e características climáticas na região de Votuporanga (SP) como assinaladas por BRUNINI et al. (2006). Esses autores salientam que em regiões com temperaturas noturnas elevadas pode ser comprometido o rendimento em grãos da cultura. Em função de riscos de elevadas temperaturas no florescimento ou na formação de espigas pode ser comprometida a viabilidade de formação de espigas e dos grãos e reduzida a produtividade. Nos resultados verificados no Projeto Milho do IACCampinas-SP, para a Região Oeste do Estado, valores médios de produtividade de 50 variedades de híbridos simples e triplos, na safra de 2005/2006 foram de $6.887 \mathrm{~kg} \mathrm{ha}^{-1}$, para um estande de população média de 56.984 plantas por hectare. Valores similares foram obtidos neste estudo, cuja média de produtividade em sistema de adensamento da cobertura morta, independentemente da época, foi de $5.762 \mathrm{~kg} \mathrm{ha}^{-1} \mathrm{e}$, no sistema não adensado, $5.199 \mathrm{~kg}$ $\mathrm{ha}^{-1}$. Esses resultados evidenciam possível favorecimento à produtividade, devido à maior cobertura com palha. Segundo KLUTHCOUSKI et al. (2006), somente em solos com SPD estabelecido, com aporte contínuo de palha e teor adequado de MO, a adubação nitrogenada pode ser antecipada, em anos com chuvas regulares. Esse processo seria fatível em solos férteis no cerrado, onde não há probabilidade de chuvas intensas em pré-semeadura. No estudo, fica em evidência que o "plantio direto", como o realizado neste estudo, sem preocupação com a manutenção da superfície de solo coberta e planejamento de rotação de culturas, a adubação antecipada não é favorecida, ainda mais com reduzida atividade microbiana e solo de escassa fertilidade.

Maiores produtividades em milho foram obtidas em cobertura tradicional com N em Palmital (SP), em solo argiloso e Votuporanga (SP), em solo arenoso, que quando efetuada cerca de um mês antes da semeadura (CANTARELla et al., 2005). Cabe notar que, nos três tratamentos de épocas, quanto à produtividade, houve tendência para maior valor no sistema de manejo com adensamento de palha, em relação ao não adensado. Por outro lado, as produtividades médias entre as épocas, independentemente do adensamento, foram de 4.758, 5.860 e $5.825 \mathrm{~kg} \mathrm{ha}^{-1}$, quando efetuados os primeiros parcelamentos de $\mathrm{N}$-fertilizante, respectivamente, aos 59 e 22 dias antes da semeadura e aos 22 dias após semeadura. Na primeira aplicação aos 21 dias antes da semeadura e em cobertura tradicional, não houve diferenças significativas. 
As maiores concentrações de $\mathrm{N}$-foliar nesses tratamentos (Figura 6), estavam relacionadas à maior concentração de $\mathrm{N}$ nos grãos, embora não tenha sido observada diferença significativa entre as épocas. Segundo MARSCHNER (1995), na fase de enchimento de grãos, as reservas de $\mathrm{N}$ da fração foliar são translocadas e armazenadas nesses órgãos, na forma de proteínas e aminoácidos. Quanto à concentração de nutrientes no grão, Bull (1993) constatou que, para uma produtividade de $5,9 \mathrm{t} \mathrm{ha}^{-1}$, similar à obtida neste trabalho, são requeridos, por tonelada de grãos produzida, 22,6; 4,$7 ; 6,5$ e $2,1 \mathrm{~kg}$ de $\mathrm{N}, \mathrm{P}, \mathrm{K}$ e $\mathrm{S}$ respectivamente. Comparando-se com os resultados da Tabela 2, todos os teores foram inferiores: 15,0; 3,3; 2,2 e $1,0 \mathrm{~kg}$ de $\mathrm{N}$; P; K e S, respectivamente, considerando-se os valores médios em todos os tratamentos. Esses resultados são indicativos da deficiência nutricional da cultura. A única diferença entre os sistemas de manejo de cobertura morta foi a observada em relação ao enxofre, sendo superior na condição de não-adensamento, também com uma evidente diminuição quando feita a adubação em cobertura, em ambos os adensamentos de palha.
As maiores concentrações de $\mathrm{P}$ no grão foram detectadas com a aplicação antecipada de N, sendo inferiores na aplicação tradicional. Fato similar foi observado quanto à concentração de $\mathrm{K}$ e $\mathrm{S}$ nos grãos. Como se sabe, com o $\mathrm{N}$ é estimulado o efeito sinérgico de assimilação de P, K e S na planta (Bull, 1993), indicativo de que, provavelmente, haja mais tempo para absorção desses nutrientes pela planta, quando efetuada a cobertura de $\mathrm{N}$ mais antecipada, logo após a semeadura do milho. Segundo Coelho (2006), o padrão de absorção de potássio é diferente em relação ao do nitrogênio e do fósforo. Considerando-se a máxima absorção no período de desenvolvimento vegetativo, com elevada taxa de acúmulo nos primeiros 30 a 40 dias de desenvolvimento, com taxa de absorção superior às de nitrogênio e fósforo, sugere-se mais necessidade de potássio na fase inicial como um elemento de "arranque". Para o nitrogênio e o fósforo, no milho há dois períodos de máxima absorção: durante as fases de desenvolvimento vegetativo e reprodutivo ou de formação da espiga, e menores taxas de absorção no período compreendido entre a emissão do pendão e o início da formação da espiga.

Tabela 2. Produtividade de grãos de milho e concentração de nitrogênio, fósforo, potássio e enxofre no grão,em cultura submetida a três épocas de aplicação de $\mathrm{N}$, sobre duas condições de adensamento de cobertura morta na safra 2005-2006. Votuporanga (SP) $\left.{ }^{1}\right)$

\begin{tabular}{|c|c|c|c|c|c|c|}
\hline Época & $\begin{array}{l}\text { Manejo da } \\
\text { cobertura morta }\left({ }^{2}\right)\end{array}$ & $\begin{array}{c}\text { Produtividade } \\
\text { de grãos }\end{array}$ & $\begin{array}{c}\text { N-total } \\
\text { grão }\end{array}$ & $\begin{array}{l}\text { P-total } \\
\text { grão }\end{array}$ & $\begin{array}{c}\text { K-total } \\
\text { grão }\end{array}$ & $\begin{array}{l}\text { S-total } \\
\text { grão }\end{array}$ \\
\hline & & $\mathrm{kg} \mathrm{ha}^{-1}$ & 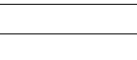 & $\varepsilon$ & & \\
\hline \multirow{3}{*}{59 d.a.s. $\left({ }^{2}\right)$} & Adensado & $4.954 \mathrm{Bb}$ & $14,9 \mathrm{Aa}$ & 4,1 Aa & $3,0 \mathrm{Aa}$ & $0,9 \mathrm{Ba}$ \\
\hline & Não adensado & $4.561 \mathrm{Bb}$ & $14,5 \mathrm{Aa}$ & 3,7 Aa & 1,7 Ba & $1,5 \mathrm{Aa}$ \\
\hline & Adensado & $6.241 \mathrm{Aa}$ & $15,4 \mathrm{Aa}$ & 3,7 Aa & $1,8 \mathrm{Ab}$ & $0,9 \mathrm{Ba}$ \\
\hline 21 d.a.s. & Não adensado & 5.479 Aab & $15,2 \mathrm{Aa}$ & $3,5 \mathrm{Aa}$ & $2,1 \mathrm{Aa}$ & $1,5 \mathrm{Aa}$ \\
\hline Cobertura & Adensado & $6.092 \mathrm{Aa}$ & $14,6 \mathrm{Aa}$ & $1,9 \mathrm{Bb}$ & 1,9 Aab & $0,5 \mathrm{Aa}$ \\
\hline tradicional & Não adensado & $5.558 \mathrm{Aab}$ & $15,2 \mathrm{Aa}$ & $2,7 \mathrm{Ab}$ & 2,7 Aa & $0,6 \mathrm{Ab}$ \\
\hline DMS (entre épocas) & & 1.138 & 1,2 & 0,7 & 1,1 & 0,5 \\
\hline DMS (entre manejos) & & 930 & 1,0 & 0,6 & 0,9 & 0,4 \\
\hline $\mathrm{CV}(\%)$ & & 9,5 & 3,7 & 10,4 & 22,5 & 23,4 \\
\hline
\end{tabular}

$\left({ }^{1}\right)$ Entre adensamentos para cada época, as médias seguidas de letras maiúsculas iguais, não são diferentes significativamente entre si pelo teste de Tukey ao nível de 0,05. Entre épocas, dentro de cada adensamento, as médias seguidas de letras minúsculas iguais, não são diferentes significativamente entre si pelo teste de Tukey ao nível de 0,05.

${ }^{2}$ ) Adensado: $5.120 \mathrm{~kg}$ ha-1 de massa de matéria seca de cobertura de solo e não adensado: $3.648 \mathrm{~kg}$ ha-1.

$\left({ }^{3}\right)$ d.a.s. $=$ dias após semeadura

\section{CONCLUSÕES}

1. A atividade respiratória da biomassa microbiana do solo não é negativamente afetada pela adubação nitrogenada em cobertura e adensamento de palha de cobertura morta, mas pela umidade do solo após a ocorrência de precipitação pluvial.

2. Em solos arenosos com reduzido teor de matéria orgânica e fertilidade, característicos da
Região Noroeste Paulista, é mais conveniente efetuarse a adubação nitrogenada tradicional em cobertura, de forma parcelada, posterior à semeadura de milho.

\section{AGRADECIMENTOS}

O autor deste estudo agradece os recursos financeiros outorgados pela Fundação AGRISUS/ 
FEALq e aos pesquisadores Dr. Heitor Cantarella e Dra. Sueli dos Santos Freitas pelas sugestões fornecidas para a elaboração do trabalho. Tornam-se extensivos os agradecimentos ao pessoal de Apoio à Pesquisa do Pólo Regional Noroeste Paulista que participou das atividades de campo.

\section{REFERENCIAS}

ALBUQUERQUE, F. A. DE, BORGES, L.M., IÁCONO, T.O., CRUBELATI, N.C.S, SINGER, A.C. Avaliação da eficiência de inseticidas no controle de percevejo e cigarrinha em milho. 2006. Disponível em: <http://www.infobibos.com/Artigos/ 2006_3/eficiencia/index.htm>. Acesso em: 2/1/2007.

ARAÚJO, A.S.F. Biodegradação, extração e análise de glifosato em dois tipos de solo. 2002. 72f. Dissertação (Mestrado). Escola Superior de Agricultura Luiz de Queiroz. Piracicaba, SP.

ARGENTA, G.; SILVA, P.R.F.; SANGOI, L. Arranjo de plantas em milho: análise do estado-da-arte. Ciência Rural, Santa Maria, v.31, n.6, p.1075-1084, 2001.

ASSIS, E.P.M.; CORDEIRO, M.A.S.; PAULINO, H.B.; CARNEIRO, M.A.C. Efeito da aplicação de nitrogênio na atividade microbiana e na decomposição da palhada de sorgo em solo de cerrado sob plantio direto. Pesquisa Agropecuária Tropical, Goiânia, v.33, n.2, p.107-112, 2003.

BASSO, C.J.; CERETTA, C.A.; MARCOLAN, A.L.; DURIGON, R. Manejo do nitrogênio no milho cultivado em sucessão a plantas de cobertura de solo no inverno, no sistema plantio direto. In: REUNIÃO BRASILEIRA DE FERTILIDADE DO SOLO E NUTRIÇÃO DE PLANTAS, 23, 1998, Caxambu. Resumos... Lavras: UFLA, SBCS, SBM, 1998. v.1, p.145.

BRUNINI, O.; ABRAMIDES, P.L.G.; BRUNINI, A.P.C.; CARVALHO, J.P. Características macroclimáticas, agrometeorológicas e restrições ambientais para o cultivo de milho em regiões tropicais baixas. Infobibos, Campinas, vol. 1, 2006. Artigo em hipertexto disponível em <http:// www.infobios.com/Artigos/2006_3/ambientemilho/ index.htm>. Acesso em: 2/1/2007.

BÜLL, L.T. Cultura do milho: fatores que afetam a produtividade. In: BULL, L.T.; CANTARELLA, H. (Ed.). Piracicaba: Potafos, 1993. p. 63-145.

CANTARELLA, H.; LERA, F.L.; BOLONHEZI, D.; LARA CABEZAS, W.A.R.; TRIVELIN, P.C.O. Antecipação de N em milho em sistema plantio direto usando ${ }^{15} \mathrm{~N}$-uréia. In: CONGRESSO BRASILEIRO DE CIÊNCIA DE SOLO, 29., 2003, Ribeirão Preto, Sociedade Brasileira de Ciência de Solo, 2003. (CD-Rom).

CANTARELLA, H.; DUARTE, A.P. ANDRADE, C.A. Manejo de nitrogênio e de matéria orgânica em milho no sistema plantio direto. In: FANCELLI, A.L. \& NETO, D.D. (Ed.). Milho Tecnologia \& Produção. Piracicaba: ESALQ/USP/ LVP, 2005. p.59-82.
CHEN, C.; XU, Z.; HUGHES, J. Effects of nitrogen fertilization on soil nitrogen pools and microbial properties in a hoop pine (Araucaria cunninghamii) plantation in southeast Queensland, Australia. Journal Biology and Fertility of Soils, Heidelberg, v.36, n.4, p. 276-283, 2002.

COELHO, A.M.; CRUZ, J.C.; FILHO, I.A.P. Rendimento do milho no Brasil: Chegamos ao máximo? Piracicaba: Potafos, 2003, 12p. (Encarte de Informações Agronômicas, 101)

COELHO, A.M. Nutrição e Adubação do Milho. Sete Lagoas: Embrapa, 2006, 10p. (Circular Técnica 78)

CONCEIÇÃO, P.C.; AMADO, T.J.C.; MIELNICZUK, J.; SPAGNOLLO, E. Qualidade do solo em sistemas de manejo avaliada pela dinâmica da matéria orgânica e atributos relacionados. Revista Brasileira de Ciência de Solo, Viçosa, v.29, n.5, p.777-788, 2005.

DA ROS, C.O.; SALETI, R.L.; PORN, R.L.; MACHADO, J.N.C. Disponibilidade de nitrogênio e produtividade de milho e trigo com diferentes métodos de adubação nitrogenada no sistema plantio direto. Ciência Rural, Santa Maria, v.33, n.5, p. 799-804, 2003.

DA SILVA, E. C.; FERREIRA, S.M.; SILVA G.P.; ASSIS, R.L.; GUIMARÃES, G.L. Épocas e formas de aplicação de nitrogênio no milho sob plantio direto em solo de cerrado. Revista Brasileira de Ciência de Solo, Viçosa, v.29, n.5, p.725-733, 2005.

DA SILVA, P. R. F.; ARGENTA, G.; SANGOI, L.; STRIEDER, M. L.; DA SILVA, A. A. Estratégias de manejo de coberturas de solo no inverno para cultivo do milho em sucessão no sistema semeadura direta. Ciência Rural, Santa Maria, v.36, n.3, p.10111020,2006

DE-POLLI, H.; GUERRA, J. G. M. Determinação do carbono da biomassa microbiana do solo: método de fumigação-extração. Seropédica: Embrapa-CNPAB, 1997. 10p. (Documentos, 37)

EMBRAPA. Centro Nacional de Pesquisa de Solos. Sistema Brasileiro de Classificação de Solos. Brasília, 1999. 412p.

ERNANI, P.R.; SANGOI, L.; LECH, V.A.; RAMPAZZO, C. A forma de aplicação da uréia e dos resíduos vegetais afeta a disponibilidade de nitrogênio. Ciência Rural, Santa Maria, v.35, n.2, p.360-365, mar-abr, 2005.

ESPINDOLA, J.A.A.; ALMEIDA, D.L.;GUERRA, J.G.M.;SILVA, E.M.R. Flutuação sazonal da biomassa microbiana e teores de nitrato de amônio de solo coberto com Paspalum notatum em um agroecossistema. Floresta e Ambiente, Viçosa, v.8, n.1, p.104-113, 2001.

FERREIRA, A.C.B.; ARAÚJO, G.A.A.; PEREIRA, P.R.G.; CARDOSO, A.A. Características agronômicas e nutricionais do milho adubado com nitrogênio, molibdênio e zinco. Scientia Agrícola, Piracicaba, v.58, n.1, p.131-138, 2001.

FORSTHOFER, E.L.;SILVA, P.R.F.;STRIEDER, M.L.; MINETTO, T.; RAMBO,L.; ARGENTA,G.;SANGOI, L.; SUHRE, E.; SILVA, A.A. Desempenho agronômico e econômico do milho em diferentes níveis de manejo e épocas de semeadura. Pesquisa Agropecuária Brasileira, Brasília, v.41, n.3, p.399-407, 2006. 
GHOSHAL, N.; SINGH, K.P. Effects of farmyard manure and inorganic fertilizer on the dynamics of soil microbial biomass in a tropical dryland agroecosystem. Journal Biological and Fertility of Soils, Heidelberg, v.19, n.2-3, p. 231-238, 1995.

JONASSON, S.; MICHELSEN, A.; SCHMIDT, I.K.; NIELSEN, E.V.; CALLAGHAN, T.V. Microbial biomass C, N and P in two arctic soils and responses to addition of NPK fertilizer and sugar: implications for plant nutrient uptake. Journal Oecologia, Heidelberg, v.106, n.4, p. 507-515, 1996.

KLUTHCOUSKI, J.; AIDAR, H.; THUNG, M.; OLIVEIRA, F.R.A. Manejo antecipado do nitrogênio nas principais culturas anuais. Piracicaba: Potafos, 2006. (Informações Agronômicas, 113)

LARA CABEZAS, W.A.R.; ALVES, B.J.R.; CABALLERO, S.S.U.; SANTANA, D.G. Influência da cultura antecessora e da adubação nitrogenada na produtividade de milho em sistema plantio direto e solo preparado. Ciência Rural, Santa Maria, v.34, n.4, p.1005-1013, 2004.

LIRA, A.C.S.; POGGIANI, F.; GONÇALVES, J.L.M. Respiração do solo sob eucalipto e cerradão. Scientia Forestalis, Piracicaba, n.56, p.15-28, 1999.

MALAVOLTA, E.; VITTI, G.C,; OLIVEIRA, S.A Avaliação do estado nutricional das plantas: princípios e aplicações. Piracicaba: Potafos, 1997. 319p.

MARSCHNER, H. Mineral nutrition of higher plant. 2.ed. New York: Academic Press, 1995. 889p.

MOREIRA, F.M.S.; SIQUEIRA, J.O. Microbiologia e bioquímica do solo. Lavras: UFLA, 2002. 626p.

PASSIANOTO, C. C.; CASTILHOS, D.D.; CASTILHOS, R.M.V.; LIMA, A.C.R.; LIMA, C.L. R.

Atividade e biomassa microbiana no solo com a aplicação de dois diferentes lodos de curtume. Revista Brasileira de Agrociências, Pelotas, v.7, n.2, p.125-130, 2001.

PÖTTKER, D.; WIETHÖLTER, S. Épocas e métodos de aplicação de nitrogênio em milho cultivado no sistema plantio direto. Ciência Rural, Santa Maria, v.34, n.4, p.1015-1020, 2004.

SAKAMOTO, K.; OBA, Y. Effect of fungal to bacterial biomass ratio on the relationship between $\mathrm{CO}_{2}$ evolution and total soil microbial biomass. Journal Biology and Fertility of Soils, Heidelberg, v.17, n.1, p.39-44, 1994.

SANTOS, G.A.; CAMARGO, F.A.O. Fundamentos da matéria orgânica do solo: ecossistemas tropicais e subtropicais. Porto Alegre: Gêneses, 1999. 508p.

TORMENA, C.A.; FREIDRICH, R.; PINTRO, J.C.; COSTA, A.C.S.; FIDALSKI, J. Propriedades físicas e taxa de estratificação de carbono orgânico num LATOSSOLO VERMELHO após dez anos sob dois sistemas de manejo. Revista Brasileira de Ciência de Solo, Viçosa, v.28, n.6, p.1023-1031, 2004.

TREZZI, M.M.;VIDAL, R.A. Potencial de utilização de cobertura vegetal de sorgo e milheto na supressão de plantas daninhas em condição de campo: II Efeitos da cobertura morta. Planta Daninha, Viçosa, v.22, n.1, p.1-10, 2004.

WANG,M.; GONG,M.; ZANG, H.;HUA, X.; YAO, J.; PANG, Y.; YANG, Y. Effect of Methamidophos and Urea Application on Microbial Communities in Soils as Determined by Microbial Biomass and Community Level Physiological Profiles. Journal of Environmental Science and Health, Part B: Pesticides, Food Contaminants, and Agricultural Wastes, and Agricultural Wastes, Philadelphia, v.41, n.4, p. 399-413, 2006.

YANO, G. T.; TAKAHASHI, H. W.; WATANABE, T.S. Avaliação de fontes de nitrogênio e épocas de aplicação em cobertura para o cultivo do trigo. Ciências Agrárias, Londrina, v.26, n.2, p.141-148, 2005.

XAVIER, F. A. DA SILVA; MAIA, S. M. F.; OLIVEIRA, T.S.; MENDONÇA, E. S. Biomassa microbiana e matéria orgânica leve em solos sob sistemas agrícolas orgânico e convencional na Chapada de Ibiapaba - CE. Revista Brasileira de Ciência de Solo, Viçosa, v.30, n.2, p.247-258, 2006. 